\title{
ESTUDO DA VIABILIDADE FINANCEIRA DO APROVEITAMENTO DE MACHOS DO
}

\section{BOVINO LEITEIRO}

\author{
Marlon Cesar Bazeggio ${ }^{1}$ \\ https://orcid.org/0000-0002-7831-5518 \\ Cesar Augustus Winck ${ }^{2}$ \\ https://orcid.org/0000-0002-9829-1824 \\ Recebido em: 25 nov. 2020 \\ Aceito em: 15 maio 2021
}

\begin{abstract}
Como citar este artigo: BAZEGGIO, M. C.; WINCK, C. A. . ESTUDO DA VIABILIDADE FINANCEIRA
\end{abstract} DO APROVEITAMENTO DE MACHOS DO BOVINO LEITEIRO. Revista Visão: Gestão

Organizacional, Caçador (SC), Brasil, v. 10, n. 1, p. 112-125, 2021. DOI:

10.33362/visao.v10i1.2458. Disponível em:

https://periodicos.uniarp.edu.br/index.php/visao/article/view/2458.

Resumo: O presente trabalho de conclusão de curso, em formato de artigo científico, tem como objetivo analisar a viabilidade financeira do aproveitamento de machos oriundos da bovinocultura de leite como complemento de renda, considerando que esses animais são descartados pela maioria das propriedades. Para isto, foi realizado um estudo de caso, em que o autor realizou a coleta de dados in loco, em uma propriedade na região Oeste de Santa Catarina, onde a produção leiteira é destaque no Estado e tem considerável participação a nível nacional. O embasamento teórico do trabalho, baseou-se no Agronegócio, atividade de suma importância para a economia do Brasil. Também fundamentada área de produção da bovinocultura de leite, e no crescente aumento do manejo desta espécie, considerando o aumento do consumo de carne bovina de animais jovens. Por fim, foram feitas as considerações teóricas a respeito da viabilidade financeira, foco do presente trabalho. Dentro da pesquisa, foram coletados dados financeiros que permitiram calcular a viabilidade do projeto para a propriedade que tem como atividade-chave a produção de leite. Concluiu-se que a atividade é viável financeiramente, além de ser um complemento de renda para a propriedade, trazendo benefícios de sustentabilidade e utilização destes animais como fonte de renda extra.

Palavras-Chave: Indicadores. Viabilidade financeira. Agronegócio. Bovinocultura de leite. Produção de carne.

FINANCIAL VIABILITY STUDY OF USING DAIRY CATTLE MALE

Abstract: The present study aims to analyze the financial viability of using dairy cattle males as an income supplement, since this animal is discarded by most dairies. For this, a case study was carried out, in which the author performed the data collection in loco,

\footnotetext{
${ }^{1}$ Estudante do Curso de Administração / Uniarp. E-mail: marlonbazeggio01@gmail.com.

2 Doutor em Agronegócios (UFRGS). Docente da Uniarp. E-mail: cesar.augustus@uniarp.edu.br.
} 
which guaranteed the veracity of the data, in a property in the West region of Santa Catarina State, where dairy production is prominent in the state and has great participation at national level. The theoretical basis of the work was based on Agribusiness, an activity of paramount importance for the economy of Brazil. Also based on the definition of dairy cattle, and on the growing increase in the handling of this animal, especially with the increase in gourmet consumption. Finally, theoretical considerations were made regarding financial viability, the focus of the present work. Within the research, financial data were collected that allowed calculating the feasibility of the project for the property whose key activity is milk production. It was concluded that the activity is financially viable and besides being an income supplement for the property, it brings sustainability and humanization benefits to these cattle.

Keywords: Financial viability. Agrobusiness. Dairy Cattle. Beef Bovine.

\section{INTRODUÇÃO}

A produção de leite gerou $\mathrm{R} \$ 3.456 .288 .000,00$ para a economia brasileira somente no estado de Santa Catarina em 2018. O Estado, ocupa a 5a (quinta) posição no ranking de maiores produtores de leite do Brasil (IBGE, 2018). Dentro do Estado, a região Oeste é a que tem a cultura de produção de leite mais desenvolvida, produzindo 2.146 bilhões de litros de leite/ano (ALIANÇA LÁCTEA SUL BRASIL, 2013).

Em 2018, o Brasil contava com um rebanho de 16.357 .485 cabeças de vacas ordenhadas (IBGE, 2019). Mathias (2019) explica que o tempo de gestação de uma vaca leiteira, é de 9 a 10 meses, sendo assim, o número de bezerros nascidos no mesmo ano foi de 16.357.485. Destes, a probabilidade de sexualidade ser macho ou fêmea é de 50\%. Os bezerros nascidos fêmeas, são aproveitados para a continuidade do processo de produção leiteira das propriedades. Já os bezerros machos, segundo Neiva et al. (2011) são vistos como problemas, sacrificados ao nascer ou criados em condições ruins de manejo que comprometem o desenvolvimento do bovino e a conversão de alimento em peso, acarretando maiores custos.

Esta pesquisa, buscou analisar a viabilidade financeira do aproveitamento de bezerros machos do bovino leiteiro para a cultura de corte, gerando uma opção de complemento de renda para o produtor de leite. Pesquisas anteriores, constataram que, o payback do projeto de criação dos machos do bovino leiteiro para corte é calculado em 3 anos, sendo que a remuneração do trabalho é de viabilidade relativa, e que aproximadamente $80 \%$ dos custos variáveis do projeto são atribuídos à alimentação (PORAZZI, 2016). Os animais apresentam bom desempenho e qualidade de carne variando de boa para ótima quando bem manejados (NEIVA et al., 2011).

Para atender ao objetivo proposto, o artigo possui como lócus de análise uma propriedade rural na região do Meio-Oeste de Santa Catarina, município de Caçador na localidade Linha Caixa D’água, tendo como proprietária a senhora Cristiane Castelani Brand. A 
propriedade em questão, possui um rebanho de 118 bovinos, entre vacas leiteiras em lactação, novilhas prenhas e novilhos machos. A produtora fez o experimento de confinar 12 novilhos machos utilizando o programa de manejo alimentar desenvolvido pela Alisul Alimentos (SUPRA). A propriedade dispõe de estrutura já instalada para a acomodação e criação destes bovinos.

O trabalho buscou a contribuição prática na propriedade, analisando os dados fornecidos pela proprietária para calcular a viabilidade financeira e a rentabilidade da atividade realizada, trazendo ainda uma questão de sustentabilidade e garantindo condições humanitárias em todos os momentos que precedem o abate destes machos.

O artigo está subdivido em cinco seções, sendo a primeira esta introdução, seguida do referencial teórico, metodologia, resultados e discussões, e finalmente foram tecidas as considerações finais.

\section{FUNDAMENTAÇÃO TEÓRICA}

Inicialmente, apresenta-se o conceito de agronegócio, seguido do macho do bovino leiteiro, e, por fim, viabilidade financeira.

\section{AGRONEGÓCIO}

O agronegócio é definido por Marcelino, Sverzutti e Trizolio (2020) como o agrupamento de diversas atividades de produção e sub-produção de produtos e materiais derivados da agricultura e pecuária. "O agronegócio tem destaque no mundo econômico devido a sua grande capacidade produtiva e geração de empregos" (MARCELINO; SVERZUTTI; TRIZOLIO, 2020, p. 128). Além de fornecer produtos para o consumo direto, o agronegócio também auxilia diversas indústrias a manterem a fabricação de seus produtos com o abastecimento de matéria-prima e suprimentos. Para John H. Davis e Ray A. Goldeberg (1957, apud DESAI 1974, tradução nossa), o agronegócio se caracteriza pela soma de todas as operações envolvidas na fabricação e distribuição de insumos agrícolas, desde a atividade de produção nas fazendas e propriedades rurais, até o armazenamento, processamento e distribuição que são feitos a partir deles. Malafaia et al. (2020) definem a estrutura do agronegócio na Figura 1. 
Figura 1 - Agronegócio

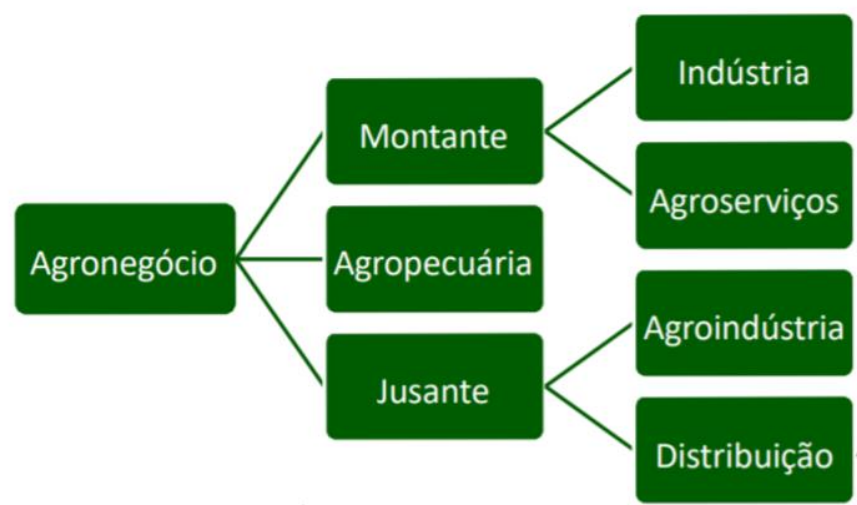

Fonte: Malafaia et al. (2020, p. 09)

Freitas (2020), infere que é necessário evidenciar que o agronegócio está envolvido em diversos setores da economia, desde os bancos com o fornecimento de crédito ao produtor, incluindo laboratórios que trabalham no desenvolvimento genético de produtos que melhoram a produtividade no campo, também, presente na indústria de transformação e em demais setores. Devido a sua interatividade entre os setores da economia, o agronegócio é responsável por uma quantidade significativa do Produto Interno Bruto (PIB) brasileiro.

O Centro de Estudos Avançados em Economia Aplicada (CEPEA), em parceria com a Confederação da Agricultura e Pecuária do Brasil (CNA) e com a Fundação de Estudos Agrários Luiz de Queiroz (FEALQ), definem agronegócio como o resultante de quatro segmentos, que são eles: (1) insumos para a agropecuária; (2) produção agropecuária básica (ou primária); (3) agroindústria (processamento) e, (4) agros serviços" (SUPERINTENDÊNCIA TÉCNICA DA CNA E CEPEA, 2020).

Malafaia et al. (2020), afirmam que em 2016 o agronegócio foi responsável por 23\% do PIB nacional anual, chegando à marca de 1,6 trilhão de reais. A CEPEA, em parceria com a CNA (2020), afirma que o PIB do agronegócio subiu 5,26\% no primeiro semestre de 2020, e apesar da pandemia, no mês de junho ainda apresentou um acréscimo de 1,31\% (SUPERINTENDÊNCIA TÉCNICA DA CNA E CEPEA, 2020). Dentro das subdivisões do agronegócio, o segmento pecuário se destaca como uma das principais cadeias produtivas de aves, bovinos, suínos e gado de leite. No segmento pecuário, a produção de bovinos aumentou o tamanho do rebanho nacional de 202 milhões em 2008, para 215 milhões em 2017, e resultou num Valor Bruto de produção (VBP) de 79,7 bilhões em 2019 (MALAFAIA et al., 2020). Ainda aproveitando o cenário favorável à criação, em 2019, segundo a equipe do Boi/CEPEA (apud CNA, 2020) foi registrado o maior nível real do preço da arroba do boi gordo desde 1994. A criação de bovinos de corte, abastece não só o mercado local, mas também o mercado internacional. Só em 2014, foram exportados 1,3 milhão de toneladas de carnes de bovino congeladas (MALAFAIA et al., 2020). 


\section{MACHO BOVINO LEITEIRO}

Dos sete países com maior contribuição para a produção mundial de leite, três deles são exportadores (Estados Unidos, Alemanha e Nova Zelândia), e quatro são economias emergentes (Índia, Paquistão, Brasil e China). O Brasil ocupa a quarta posição no ranking (STOCK; RESENDE; LEITE, 2020). Dados do IBGE mostram que o número de cabeças de vaca leiteira no Brasil era de 11.506.788 em 2017. Só em Santa Catarina eram de 689.615 cabeças. Mathias (2019), infere que o número de bezerros nascidos no ano, corresponde ao número de cabeças de vacas leiteiras. Levantando a probabilidade de $50 \%$ dos bezerros nascerem machos, e considerando uma taxa de sobrevivência de 90\%, tem-se a disponibilidade de 5.178 .055 bezerros de origem leiteira por ano, no Brasil.

"Anualmente, nas principais bacias leiteiras do Brasil, milhares de bezerros machos são sacrificados ao nascer, eliminando-se assim uma fonte de renda em potencial" (RIBEIRO et al., 2001, p. 2145). A disponibilidade destes animais é muito grande, porém, eles são vistos como problemas para os produtores. "As propriedades leiteiras em geral encaram o nascimento dos machos de leite como um problema, não havendo outra opção a não ser o descarte deste animal" (PORAZZI, 2016, p. 4).

Recentemente, o modelo mental dos produtores tem mudado, segundo Neiva et al. (2011), esses animais eram simplesmente descartados pelos pecuaristas de corte, pois não tinham a mesma capacidade de atingir os desempenhos desejados em termos de peso e carcaça para serem aceitos nos frigoríficos. Uma das opções para a criação rentável dos bovinos leiteiros, é a destinação destes animais para a produção de vitelos. "A produção de vitelos no Brasil ainda é restrita, mas existe um mercado em potencial, localizado em sua maior parte nos grandes centros e para um público de maior poder aquisitivo" (RIBEIRO et al., 2001, p. 2152).

Neiva et al. (2015), infere que "vitelo" é uma palavra originada no latim, que significa gema de ovo, o que remete as pessoas a pensarem em estruturas do pré-nascimento, e logo, no abate precoce destes animais, com idade tenra. Os vitelos podem ser classificados em dois grupos: (1) vitelo de carne branca, animal criado com a ingestão de alimentos líquidos, que é abatido pesando de 120 a $210 \mathrm{~kg}$, com aproximadamente 3 a 5 meses de idade; (2) vitelo de carne rosa, animal desaleitado precocemente e que segue uma dieta de grãos e alimentos sólidos, este, abatido com 225 a 250 kg, tendo 5 a 6 meses. (RIBEIRO et al., 2001 apud ALMEIDA JÚNIOR et al., 2008). Ribeiro et al. (2001), inferem que os bezerros leiteiros apresentam ótimo desenvolvimento no sistema de confinamento, afirmando ser viável a produção destes animais neste sistema de produção. 


\section{SISTEMA DE CONFINAMENTO BOVINO}

A nítida competitividade com outras opções de uso do solo, como a agricultura, tem forçado o setor pecuário a buscar maior eficiência produtiva e econômica dentro do segmento agropecuário. Para tanto, como estratégia para manter o fornecimento de carne para os mercados interno e externo, o bovino brasileiro é normalmente alimentado em confinamentos. Além disso, confinamentos desenvolvidos em propriedades com expressiva atividade agrícola servem como uma opção de diversificação de investimentos (MOREIRA, et al., 2010).

O objetivo principal do confinamento de bovinos é concentrar um grande número de animais em pequenas áreas, alimentando-os com dietas para o maior ganho de peso, sendo assim caracterizado como um sistema de produção (SILVEIRA, 2002), sendo viável para os produtores do Brasil, que segundo Pinto, C. L B. et al. (2015) é em sua grande maioria de pequeno a médio porte, os quais encontram pequenas margens do retorno financeiro e são sujeitas a incertezas como, por exemplo, o preço de venda do produto final e os custos de operações.

A principal variação dos sistemas de confinamento em relação ao método usual em que os animais têm acesso a pastagens é que, quando confinadas, as vacas são alimentadas no cocho e necessitam de instalações confortáveis e funcionais que proporcionem um ambiente melhor em termos de conforto térmico, para assim diminuir o estresse animal e consequentemente aumentar o seu bem-estar e sua capacidade produtiva (ROTTA et al., 2010).

\section{COMPOST BARN E A PRODUTIVIDADE LEITEIRA}

Dentre as modalidades de confinamento de gado, destaca-se o sistema Loose Housing, onde os animais ficam soltos e podem caminhar livremente dentro do galpão. Dentro dessa modalidade encontra-se o Compost Barn (CB), na qual o tipo de instalação usado para o gado leiteiro no sistema de confinamento exerce uma grande influência nos resultados de produtividade dos animais, bem como, sobre a qualidade do leite obtido. Para tanto, deve-se visar o conforto térmico, espaço físico e de cocho adequados, e o piso utilizado, com o intuito de garantir condições de higiene, sanidade e eficiência no manejo (BARBERG; ENDRES; JANNI, 2007).

Além disso, um espaço que não preze pelo conforto e sanidade dos animais pode predispor a lesões nas patas, claudicação, dermatite digital e outras lesões no casco. Por isso, considera-se sistemas de estabulação com camas mais profundas, mais confortáveis para os animais, diminuindo principalmente a incidência de lesões de jarrete. Para reduzir estes problemas, novos sistemas foram desenvolvidos para atender a demanda de melhores condições para níveis elevados de bem-estar para o gado (PILATTI, et al., 2017).

O CB é um sistema de confinamento que proporciona aos animais mais liberdade de 
movimento e conforto, além de induzir maior longevidade e um ambiente confortável, seco e seguro o ano todo. Consiste em uma grande área coberta, revestida com uma cama de maravalha de madeira seca e esterco compostado, tendo como princípio básico de funcionamento a compostagem desta cama (PILATTI, et al., 2017).

O bom funcionamento do CB depende exclusivamente da manutenção adequada da cama, sendo que o ideal é fazer o revolvimento da cama pelo menos duas vezes ao dia a uma profundidade que varia entre 15 e $25 \mathrm{~cm}$ (DAMASCENO, 2012). Essa manutenção é considerada essencial para evitar o acúmulo de umidade e compactação, além de proporcionar a incorporação do oxigênio na cama, com o intuito de aumentar a decomposição aeróbica dos dejetos e manter a superfície macia para os animais deitarem (BARBERG; ENDRES; JANNI, 2007).

Pilatti et. al (2017) definem como condições de temperatura e umidade ideias para ocorrer a compostagem do material uma temperatura entre 54 e $65^{\circ} \mathrm{C}$ e umidade entre 40 e $65 \%$.

\section{ANÁLISE DA VIABILIDADE FINANCEIRA}

Os dados contábeis oriundos das transações e negociações institucionais são importantes indicadores da real situação financeira organizacional. Para Ludícibus (2000 apud LIMA; CHACON; SILVA, 2004) a contabilidade tem como objetivo principal fornecer informações econômicas para que cada indivíduo possa basear sua tomada de decisão e fazer seus julgamentos de forma segura. Em despeito à importância para a tomada de decisões, Kruguer, Mazzioni e Boettcher (2009), inferem que a contabilidade tem importância relacionada ao controle e planejamento das atividades, além de sua participação na gestão de receitas, custos e despesas que envolvem as atividades desenvolvidas.

A obtenção do conhecimento financeiro é essencial para o melhor planejamento dos negócios. Planejar e calcular antes de realizar um investimento pode evitar possíveis perdas de dinheiro por parte do investidor. Para Reis (2018), analisar a viabilidade financeira de um projeto, envolve relacionar o investimento inicial, os custos fixos e variáveis ao longo do projeto e confrontá-los com os possíveis rendimentos que ele pode gerar com o decorrer do tempo. A viabilidade financeira avalia se os investimentos de capital e tempo necessários para a idealização de um projeto são viáveis, através de cálculos baseados em despesas e lucros (SEBRAE, 2020).

A viabilidade financeira de um projeto é calculada por meio de indicadores financeiros. Existem diferentes maneiras de calcular a viabilidade financeira de um projeto, sendo os principais indicadores: (1) Mostrar quanto tempo o projeto levará para se pagar (Payback); (2) Rentabilidade mínima para o investimento ser viável, comparado a outras opções de investimento Taxa Mínima de Atratividade (TMA); (3) Une todos os valores do fluxo de Caixa e 
os desconta com a taxa mínima de atratividade Valor Presente Líquido (VPL); (4) Rentabilidade própria do projeto TIR Taxa Interna de Retorno (TIR) (REIS, 2018).

\section{DELIMITAÇÕES METODOLÓGICAS}

A pesquisa foi operacionalizada por meio de um estudo de caso, cuja definição consiste no "estudo profundo e exaustivo de um ou poucos objetos, de maneira que permita seu amplo e detalhado conhecimento" (GIL, 2002, p. 54). O método utilizado se fez coerente com os objetivos de aplicação prática da pesquisa. O caso analisado no presente estudo, foi escolhido pelo critério de acessibilidade, haja vista que o responsável pela propriedade, precisava ter como atividade principal a leiteria, um plantel de bovinos para o fim leiteiro, e também, estar disposto a fornecer dados imprescindíveis para os cálculos de viabilidade financeira e rentabilidade da atividade, como: (1) conversão de alimento para peso; (2) custo de matéria-prima e outros.

Os dados fornecidos referem-se ao período de fevereiro a setembro de 2020, fase que durou o processo de confinamento dos bezerros macho do bovino leiteiro na propriedade. Os dados foram coletados pelo autor em setembro e outubro do mesmo ano, e a partir destes, foram realizados os cálculos de viabilidade financeira e de rentabilidade de investimento. Em seguida, foram construídos quadros para expor os dados coletados.

\section{RESULTADOS E DISCUSSÃO}

Na Tabela 1, encontram-se os números gerais da propriedade, levantados em pesquisa realizada diretamente na propriedade analisada.

Tabela 1- Números da propriedade

\begin{tabular}{llll}
\hline Levantamento de dados & Números & Tipo & Caracterização \\
\hline № de fêmeas & 69 & Matrizes em lactação & Produtoras de leite \\
\hline № de fêmeas & 21 & Novilhas & Futuras produtoras de leite \\
\hline № de fêmeas & 16 & Bezerras & Futuras novilhas \\
\hline № de machos & 12 & Bezerros & Futuro boi de corte \\
\hline Área & 22,7 & Hectares & Área total da propriedade
\end{tabular}

A propriedade dispõe de energia elétrica, água potável em abundância, com lagoas para irrigação, lagoa de tratamento de resíduos, ampla área de pastagens, barracões para armazenamento de insumos e máquinas, conta ainda com dois barracões para os animais, onde, no primeiro está instalada a leiteria que se encontra dentro das normas exigidas pela 
Companhia Integrada de Desenvolvimento Agrícola de Santa Catarina (CIDASC) e pela Vigilância Sanitária, e o segundo acomoda as outras atividades com os bovinos, incluindo o confinamento para os machos em questão, a estrutura conta com uma sobra de capacidade por opção do proprietário, uma vez que é incerta a quantidade de bezerros que terá nascido ao longo do tempo, podendo ter seu plantel aumentado ou diminuído.

O plantel total de bovinos da planta é de 118 (cento e dezoito) cabeças, sendo 69 (sessenta e nove) fêmeas matrizes produtoras de leite, 21 (vinte e uma) fêmeas novilhas futuras produtoras leiteiras em fase de inseminação, 16 (dezesseis) fêmeas bezerras em crescimento e 12 (doze) machos bezerros para confinamento. Na Tabela 2 encontram-se as despesas necessárias para a realização da atividade de confinamento, incluindo insumos e medicamentos por cabeça.

Tabela 2- Despesas por cabeça da propriedade analisada

\begin{tabular}{|c|c|c|c|}
\hline ALIMENTO/INSUMO & QUANTIDADE & RS UNITÁRIO & $\mathrm{R} \$$ TOTAL \\
\hline Leite (L) & 168 & 2,06 & $\mathrm{R} \$ \quad 346,08$ \\
\hline Ração inicial (kg) & 144,8 & 2,4 & $\mathrm{R} \$ \quad 347,52$ \\
\hline Milho (kg) & 915,85 & 0,95 & $\mathrm{R} \$ \mathbf{8 7 0 , 0 6}$ \\
\hline Ração alto grão (kg) & 200,15 & 2,125 & $\mathrm{R} \$ \quad 425,32$ \\
\hline \multirow[t]{2}{*}{ Medicamentos } & 1 & 34,5 & 34,50 \\
\hline & & DESPESA TOTAL & $\mathrm{R} \$ 2.023,48$ \\
\hline
\end{tabular}

Fonte: Autor (2020).

É possível avaliar que o principal custo para o produtor é a alimentação, com foco no milho. Isto sugere que a propriedade que dispõe da produção do próprio grão pode baixar consideravelmente os custos por período, assim obtendo maiores resultados. Outra opção que pode ajudar a baixar o custo é aproveitar as oportunidades de compra em valores mais baixos no mercado, comprando antecipadamente na baixa do grão, e estocando para atender a demanda da produção. Foi observado que o proprietário da propriedade analisada no período da aplicação da pesquisa, priorizava a compra por oportunidade no mercado, buscando o melhor valor.

Quando se fala em investimento inicial, custo fixo e investimento em infraestrutura, o mesmo não é notado. Isso porque, o bezerro em questão seria descartado, a estrutura física já existe, ficando até ociosa por grande período do ano. Em análise as faturas de energia não existem aumento de consumo, e, durante alguns meses o consumo oscila até mesmo diminuindo. Outro custo que não teve impacto nessa operação foi a de mão de obra, pois também já está disponível na propriedade, somente foi adotado maneiras para incluir a nova atividade na rotina e não atrapalhar a produção leiteira e assim supriu-se toda a necessidade da mesma.

Analisou-se que é de suma importância acompanhar a evolução de peso dos animais, 
avaliando individualmente e corrigindo possíveis estresses, como problemas de adaptação alimentar por exemplo. Outro fator importante é seguir o plano de vacinação corretamente que além dos vermífugos rotineiros desenvolvidos para a espécie bovina ainda inclui adaptadores orgânicos e vitaminas para a produção de machos dos bovinos leiteiros.

No quadro 1, foram apontados os dados de conversão alimentar dos bovinos estudados na propriedade. A conversão foi avaliada por variáveis de tempo e de tipo de alimento, o peso inicial e o peso final do quadro são extraídos por meio de balança aferida pelo Inmetro, os pesos intermediários foram coletados por meio de uma técnica onde utiliza-se uma fita métrica desenvolvida para o macho holandês que traz o peso aproximado para acompanhamento.

Quadro 1- Conversão de Alimentação em peso vivo.

\begin{tabular}{|c|c|c|c|c|}
\hline FASE/IDADE & ALIMENTO & CONSUMO & $\begin{array}{l}\text { CONSUMO } \\
\text { TOTAL UND. }\end{array}$ & PESO VIVO (Kg) \\
\hline De 01 a 04 dias & Leite Colostro (L) & Até 6L/dia & 24 & 41,6 \\
\hline \multirow{2}{*}{ De 05 a 21 dias } & Leite (L) & Até 6L/dia & 102 & \multirow{2}{*}{58,175} \\
\hline & Ração Inicial (kg) & Livre acesso & 8,5 & \\
\hline \multirow{2}{*}{ De 22 a 28 dias } & Leite (L) & Até 4L/dia & 28 & \multirow{2}{*}{63,11} \\
\hline & Ração Inicial (kg) & Livre acesso & 4,9 & \\
\hline \multirow{2}{*}{ De 29 a 35 dias } & Leite $(\mathrm{L})$ & Até 2L/dia & 14 & \multirow{2}{*}{67,59} \\
\hline & Ração Inicial (kg) & Livre acesso & 8,4 & \\
\hline De 36 a 65 dias & Ração Inicial (kg) & Livre acesso & 123 & 92,19 \\
\hline De 66 a 100 dias & $\begin{array}{l}\text { Ração alto grão com } 75 \% \text { milho } \\
\text { (kg) }\end{array}$ & Livre acesso & 203 & 132,79 \\
\hline De 101 a 130 dias & $\begin{array}{l}\text { Ração alto grão com 80\% milho } \\
\text { (kg) }\end{array}$ & Livre acesso & 249 & 182,59 \\
\hline
\end{tabular}

Fonte: Autor (2020).

A pesquisa apurou um ganho de peso de 1,303 kg/dia, totalizando ao final do processo, $273,79 \mathrm{~kg}$ por cabeça, o resultado foi de $19,26 \%$ da alimentação consumida revertida em peso vivo. A Tabela 3, aborda a receita obtida em $\mathrm{R} \$$ (reais) pela atividade de confinamento de bezerros machos de corte do bovino leiteiro, apresentando valores por cabeça na propriedade observada.

Tabela 3- Receita em R\$ (reais) por cabeça.

\begin{tabular}{lcll}
\hline PESO CARNEADO $(\mathrm{KG})$ & R\$ UNITÁRIO & $(-)$ FUN RURAL & R\$ TOTAL \\
\hline 170,31 & 17,00 & $-43,42905$ & $R \$ 2.851,84$ \\
\hline & & RECEITA TOTAL & $R \$ 2.851,84$ \\
\hline
\end{tabular}

Fonte: Autor (2020).

A proprietária comercializou os bovinos com um frigorífico da região. O preço base da 
negociação no período observado foi de $\mathrm{R} \$ 17,00 / \mathrm{kg}$ de carne, peso do boi já abatido. A conversão de peso líquido resultou em 54\% de carcaça bovina, sendo que dos 315,39 kg de peso vivo resultaram em 170,31 kg de carne. Os valores informados são resultados do cálculo da média do rebanho. Assim, na Tabela 4 foi apresentado o resultado em R\$ (reais) por cabeça confinada do bezerro macho do bovino leiteiro.

Tabela 4- Resultado por cabeça da comercialização do macho bovino.

\begin{tabular}{ll}
\hline Despesa & $\mathrm{R} \$ 2.023,48$ \\
\hline Receita & $\mathrm{R} \$ 2.851,84$ \\
\hline Resultado & $\mathrm{R} \$ 828,36$ \\
\hline
\end{tabular}

Fonte: Autor (2020).

Outro método de análise financeira utilizado na presenta pesquisa, foi o valor presente líquido (VPL). Para o cálculo foi atribuído uma taxa mínima de atratividade (TMA) de 3,0\% e o resultado do cálculo foi positivo. Infere-se através dos resultados obtidos que o confinamento do macho de bovino leiteiro é viável financeiramente.

A pesquisa não quer trazer comparativos de investimentos e sim analisar a viabilidade financeira da atividade.

\section{CONSIDERAÇÕES FINAIS}

Por meio dos resultados, é possível concluir que a atividade estudada se trata de um bom negócio para pequenas propriedades iguais a em questão nesse trabalho, utilizando da estrutura já existente é necessário agregar receita com resultado positivo obtido por meio de um subproduto antes descartado e garantindo a humanização do abate desses animais.

No caso estudado, a proprietária utilizou de um plano de manejo alimentar já existente fornecido pela empresa fabricante das rações que fizeram parte desse programa de nutrição. O sistema de instalação utilizado é muito simples, consiste no sistema compost barn, espaço físico coberto e bem arejado revestido com material seco de serragem ou maravalha proporcionando conforto e a compostagem do material da cama, sendo de fácil manejo.

Os bezerros de produção própria trouxeram confiança para que a avaliação fosse real, sendo que se têm um padrão de bezerros, com mesma genética e idade, possibilitando utilizar a média como referência para embasamento. A conversão alimentar foi de 19,26\% e o aproveitamento de carcaça de $54 \%$ após abate dos novilhos machos, um ótimo resultado para amimais dessa genética, pois não estamos falando de uma raça específica para corte e sim leiteira.

Infere-se que a maior dificuldade encontrada foi conciliar as duas atividades dentro da propriedade, pois a atividade principal é a leiteira, onde os envolvidos tiveram um grande 
esforço para que pudessem realizar as duas atividades sem comprometer nenhuma delas e mantendo o propósito de aproveitar a mesma mão de obra sem custos extras-existentes. Desta forma, conclui-se que a atividade de manejo do macho do bovino leiteiro na propriedade estudada é financeiramente viável e uma alternativa de receita para os produtores.

\section{REFERÊNCIAS}

ALIANÇA LÁCTEA SUL BRASIL. Santa Catarina. Disponível em:

http://www.aliancalactea.org.br/dados-da-regiao/santa-catarina/. Acesso em: 13 out. 2020.

ALMEIDA JUNIOR, G.A.. et al. Desempenho de bezerros holandeses alimentados após o desaleitamento com silagem de grãos úmidos ou grãos secos de milho ou sorgo. Revista Brasileira de Zootecnia, v. 37, n. 1, p.148-156, 2008.

BARBERG, A. E.; ENDRES, M. I.; JANNI, K. A. Compost dairy barns in Minnesota: A descriptive study. Applied Engineering in Agriculture, 23:2, 231-238, 2007.

DAMASCENO, F. A. Compost bedded pack barns system and computational simulation of airflow through naturally ventilated reduced model. Curso de Pós-Graduação em Engenharia Agrícola, 2012. Universidade Federal de Viçosa, Viçosa, Minas Gerais.

DESAI, D. K. Evolution of a concept of agribusiness and its application. Indian Journal of Agricultural Economics, v. 29, n. 4, p.31-43, 1974.

FREITAS, E. Agronegócios. Mundo Educação, 2020. Disponível em: https://mundoeducacao .uol.com.br/geografia/agronegocios.htm. Acesso em: 09 out. 2020.

GIL, A.C.. Como elaborar projetos de pesquisa. 4. ed. São Paulo: Atlas, 2002.

IBGE. Censo Agro 2017- Cartograma - Bovinos do Brasil por Efetivo do rebanho de vacas ordenhadas. 2019. Disponível em: https://censos.ibge.gov.br

/agro/2017/templates/censo_agro/resultadosagro/pecuaria.html?localidade=0\&tema=75653 . Acesso em: 14 out. 2020.

IBGE - Instituto Brasileiro de Geografia e Estatística. Ranking dos maiores produtores de leite do Brasil, 2018. Disponível em:

https://cidades.ibge.gov.br/brasil/sc/pesquisa/18/16459?indicador=16560\&ano=2018\&tipo=r anking. Acesso em: 13 out. 2020.

IBGE - Instituto Brasileiro de Geografia e Estatística. Tabela de produção de leite, 2018. Disponível em: https://cidades.ibge.gov.br/brasil/sc/pesquisa/18/16459?

indicador=16560\&ano=2018._Acesso em: 13 out. 2020.

IBGE. PPM 2018: rebanho bovino diminui e produtividade nacional de leite ultrapassa 2 mil litros por animal ao ano, 2019. Disponível em:https://agenciadenoticias.ibge.gov.br/agenciasala-de-imprensa/2013-agenciade-noticias/releases/25482-ppm-2018-rebanho-bovino- 
diminui-e-produtividade-nacional-de-leite-ultrapassa-2-mil-litros-por-animal-ao-ano. Acesso em: 12 out. 2020.

KRUGER, S.D.t; MAZZIONI, S.; BOETTCHER, S.F. A importância da contabilidade para a gestão das propriedades rurais. In: XVI Congresso Brasileiro de Custos, Fortaleza, 2009, Anais...

Fortaleza, 2009.

LIMA, M. R. S. ; CHACON, M.J.M. ; SILVA, M.C. Uma contribuição a importância do fluxo de informações contábeis no processo decisório das micro e pequenas empresas: uma pesquisa realizada na cidade de recife no estado de Pernambuco. In: Conferencia Internacional de Empreendedorismo Latino Americana, 2004, Rio de Janeiro. Anais... Rio de Janeiro: UFRJ, 2004.

MALAFAIA, G.C; FRAINER, D.; CASAGRANDA, Y.; BISCOLA, P.H.N; DIAS, F.R.T. Produto Interno Bruto (PIB) do Complexo Agroindustrial da Bovinocultura de Corte de Goiás: 1.ed. MS: EMBRAPA, junho/2020.

MARCELINO, J.A.; SWERZUTIT, A.R.O.; TRIZOLIO, B.L.G.S.. Agronegócio brasileiro e o comportamento do setor em meio ás crises econômicas e os impactos sofridos pela pandemia da covid-19. Boletim de Conjuntura, Boa Vista, ano II, v. 3, n. 9, p. 127-138, 2020.

MATHIAS, J. Qual o tempo de gestação por inseminação artificial nas vacas? Globo Rural, 2019. Disponível em: https://revistagloborural.globo.com/vida-na-fazenda/grresponde/noticia/2019/01/qual-o-tempo-de-gestacao-por-inseminacao-ar- tificial-nasvacas.html. Acesso em: 12 out. 2020.

MOREIRA, S. A.; THOMÉ, K. M.; FERREIRA, P. S.; BOTELHO FILHO, F. P. Análise econômica da terminação de gado de corte em confinamento dentro da dinâmica de uma propriedade agrícola. Custos e @gronegócio On Line, Recife, PE, v. 5, n. 3, p. 132-152, Mar. 2010.

NEIVA, J.N.M.; CUTRIM, D.; MACIEL, R. P.; SANTANA, A. E. M.; NEIVA, A. C. G. R.; RESTLE, J. Aproveitamento de machos de origem leiteira para produção de carne. In: 3 rd International Symposium of Dairy Cattle, 2011, St Louis, Missouri USA. Anais... Tocantins, 2011, p. 196 216.

PILATTI, J.A. et al. O comportamento diurno e o bem-estar de vacas em sistema de confinamento compost barn. 2017. Dissertação de Mestrado. Universidade Tecnológica Federal do Paraná.

PINTO, C. L.B.; RAMOS, A. P. S.; OZORIO, L. M; BRANDÃO, L. E. T. Incerteza e Flexibilidade na Pecuária de Corte Brasileira: O Valor da Opção de Confinamento. Brazilian Business Review, v. 12, n. 6, p. 102-102, 2015.

PORAZZI, T. Viabilidade do aproveitamento de terneiros leiteiros para corte, em sistema de confinamento com dieta alto grão. 2016. TCC - Trabalho de Conclusão de Curso - UNIJUí Universidade Regional Do Noroeste Do Estado Do Rio Grande Do Sul, Ijuí, 2016. 
REIS, T._Por que fazer a análise de viabilidade de um negócio é tão importante? Suno Artigos, 2018. Disponível em: https://www.sunoresearch.com.br/artigos/analise-de-viabilidade/. Acesso em: 12 out. 2020.

RIBEIRO, T.R; PEREIRA, J.C; OLIVEIRA, M.V.M; QUEIROZ, A.C.; CECON, P.R.; LEÃO, M.I.; MELO, R.C.A. Influência do Plano Nutricional sobre o Desempenho de Bezerros Holandeses para Produção de Vitelos. Revista Brasileira de Zootecnia, 30(6S), p.2145-2153, 2001.

ROTTA, P. P., Prado, R. M., Moreira, F. B. \& Prado, I. N. 2010. Suplementação do perído do verão.

SEBRAE. Viabilidade Financeira. Disponível em:_https://www. sebrae.com.br/sites/ PortalSebrae/ufs/pr/artigos/viabilidade-financeira, 4e8ccd18a819d610VgnVCM10000 04c00210aRCRD\#: :text=A\%20viabilidade\%20financeira\%20\%C3\%A9\%20um,\%C3\%A9\%20vi\% C3\%A1vel\%20para\%20seus\%20investidores. Acesso em: 04 out. 2020.

SILVEIRA, R. L. F. Análise das operações de Cross Hedge do bezerro e do Hegde do boi gordo no mercado futuro da BM\&F. 2002.

STOCK, L.A; RESENDE, J.C.; LEITE, J.L.B. Produção mundial de leite: tendências nos principais países. Anuário Leite 2020, EMBRAPA. Disponível em: https://www.embrapa.br/gado-de-leite. Acesso em: 14 out. 2020

Superintendência Técnica da CNA e CEPEA. PIB do agronegócio cresce 3,81\% em 2019. Disponível em: https://www.cnabrasil.org.br/boletins/pib-do-agronegocio-cresce-3-81-em2019. Acesso em: 15 out. 2020.

Superintendência Técnica da CNA e CEPEA. PIB do agronegócio cresceu 5,26\% no $1^{\circ}$ semestre de 2020. Disponível em: https://www.cnabrasil.org.br/boletins/pib-do-agronegocio-cresceu1-semestre-2020. Acesso em: 15 out. 2020. 